\title{
La desinformación entra por los ojos
}

\author{
Laura Teruel Rodríguez \\ Profesora Titular (Universidad de Málaga)
}

\section{Referencia de este artículo}

Teruel Rodríguez, Laura (2021). La desinformación entra por los ojos. En: adComunica. Revista Científica de Estrategias, Tendencias e Innovación en Comunicación, $\mathrm{n}^{0} 22$. Castellón de la Plana: Departamento de Ciencias de la Comunicación de la Universitat Jaume I, 369-372. DOI: http://dx.doi.org/10.6035/2174-0992.2021.22.19

Cada persona puede contar su propia historia sobre cómo ha vivido la pandemia del coronavirus, pero Emilio Morenatti ha contado la de toda la sociedad sin palabras. Ganó el Pulitzer con sus fotografías poderosas y sin artificios. La importancia de la imagen para que la opinión pública se fije en determinados acontecimientos en la saturada agenda mediática es incuestionable. La capacidad de poner el objetivo sobre la noticia y, con una instantánea potente, convertirla en central es potestad de los profesionales del fotoperiodismo. En diferentes áreas, en todos los soportes — del papel a Instagram - y a lo largo del tiempo — de lo analógico a lo digitallos recursos visuales han reivindicado su valor informativo.

El periodismo gráfico ha experimentado, cuanto menos, las mismas crisis y amenazas que el escrito. No está exento de las dificultades que la ola de desinformación está ocasionando al periodismo. Y, aunque no se trata de un fenómeno reciente, la deriva actual puede ser incierta si desde la sociedad, la profesión y la Universidad no se reacciona de manera vigorosa y coordinada.

Sobre los orígenes del fenómeno, en la memoria colectiva aún está la imagen del cormorán cubierto de crudo, en 1991, que se usó como símbolo del ecoterrorismo 
de Sadam Hussein al inicio de la Guerra del Golfo por parte de Estados Unidos y que después se supo que no correspondía a esos hechos. En 2003, Colin Powell, secretario de Estado del mismo país, esgrimió unas capturas del servicio de inteligencia para defender la guerra contra Irak por posesión de armas de destrucción masiva. Los presidentes que respaldaron la acción bélica —inmortalizados en la, a su vez, icónica foto del trío de las Azores - han reconocido posteriormente el error cometido por darle credibilidad a unas reproducciones con poca definición. Pero la ofensiva militar se prolongó durante años y costó vidas.

En ambos momentos, nos hallamos ante material gráfico instrumentalizado que sirvió de base para instaurar un clima de opinión favorable a determinadas acciones geopolíticas. En la referencial clasificación de Wardle y Derakshian (2017) se utilizaron para estrategias de disinformation, contenidos que se crean o interpretan con la intención de perjudicar a un objetivo o movilizar a la opinión pública en un determinado sentido.

Frente a estos casos, en enero de 2013, El País llevó en portada una foto falsa del presidente venezolano Hugo Chávez hospitalizado grave. El diario, que asumió el error y posteriormente hizo de él una lección sobre verificación del material gráfico, incurrió en un caso de misinformation en tanto publicó contenido falaz a causa de la falta de diligencia profesional en el contraste de los datos.

Este caso puede considerarse, a su vez, una muestra de malinformation en tanto saca a la luz imágenes de la vida privada para infligir daño; como la publicación de robados de la esfera íntima de la actriz Julie Gayet y el presidente francés François Hollande, en 2014, contra los que pesa una sentencia judicial.

Pero decíamos que la información gráfica aborda cuanto menos las mismas amenazas que la escrita pues también hay manifestaciones propias de la desinformación en el ámbito de la imagen. La llegada de la fotografía digital no sólo a las redacciones sino, sobre todo, su extensión a toda la ciudadanía ha crecido en paralelo al desarrollo de aplicaciones que permiten tratar y, dado el caso, manipular la imagen con sencillez, hasta la construcción de las temidas deepfakes.

Durante las elecciones presidenciales brasileñas de 2018 se demostró que el 60\% de los contenidos difundidos en Whatsapp sobre las mismas era total o parcialmente falso y que, en más del $80 \%$ de los casos, estos posts contenían imagen creada por los usuarios (Canavilhas, Colussi y Moura, 2019). En torno al referéndum catalán del 1 de octubre de 2017, la manipulación de los recursos audiovisuales para ponerlos en circulación por las redes sociales fue uno de los métodos más eficientes para amplificar los mensajes (Aparici, Rincón-Manzano y García-Marín, 2019).

La democratización del acceso a la labor informativa, en el sistema híbrido de medios, favorece que sean múltiples las voces que nutren a la opinión pública (Palomo y Guerrero- García, 2015). Para hacerse ver, se cae en la tentación de editar o manipular las imágenes para que sean más espectaculares (Alper, 2013) y, por 
tanto, más atractivas para los algoritmos que se mueven a golpe de clickbait. Sucede frecuentemente cuando es la ciudadanía la que asume labores periodísticas (Lemos, Bitencourt y Bastos dos Santos, 2020), pero no sólo entonces. El fotoperiodismo de guerra acometió una reflexión sobre el retoque de la imagen y la fina línea, que se había traspasado en ocasiones, del falseamiento de contenidos para hacerla más impactante (Lavín de las Heras y Chivite Fernández, 2015).

Agencias de verificación como Maldita.es evidencian la importancia de la imagen manipulada para la viralización de las mentiras. En su informe de junio 2021 «Desinformación en Whatsapp» se explica que ocho de los diez bulos de los que más alertas les hicieron llegar por esta red social contaban con imagen fija (seis) o vídeo (dos). Desde este proyecto informativo abrieron un canal para que la audiencia les transmitiera las informaciones que les parecieran poco creíbles. Porque la ciudadanía está preocupada por el auge de los contenidos falsos y entiende la labor de la verificación que desarrollan los medios.

Este punto, la importancia del interés ciudadano y la alfabetización mediática es el primero para intentar contener el avance de los bulos audiovisuales que cada vez se crean con un mayor nivel de sofisticación. Medios como Maldita.es recogen herramientas de chequeo para que, individualmente, podamos comprobar la veracidad de los contenidos que nos llegan. Del mismo modo, gigantes tecnológicos como Google o Microsoft ofrecen aplicaciones y formación gratuita también porque, aunque, en un primer momento, actores como Facebook intentaron abstraerse de los desórdenes informativos que fluían por sus páginas, son conscientes de qué lado deben estar para la opinión pública.

Así pues, junto con la labor de una sociedad formada en lenguaje informativo audiovisual y la tecnología, estos retos que afronta el periodismo gráfico deben ser combatidos, ante todo, desde la Universidad y los profesionales y medios de comunicación. Las graves consecuencias de la seudoinformación, en términos geopolíticos o sanitarios requieren un fortalecimiento de las habilidades de verificación de la información especializada, de creación de contenidos multimedia para internet y de la deontología que debe guiar el tratamiento gráfico en los planes de estudio de Periodismo.

El perfeccionamiento de los procedimientos de adulteración requiere la capacitación tecnológica de los periodistas de todos los ámbitos y una actualización continua de conocimientos. Existen nuevas herramientas que deben añadirse a las que hasta ahora formaban parte de las rutinas profesionales para verificar el origen de las imágenes: conocer si se ha usado previamente; consultar sus metadatos; datarla y geolocalizarla y comprobar, por ejemplo, si los factores meteorológicos respaldan que fue realizada cuándo y dónde se dice; o detectar ediciones o manipulaciones sobre el contenido. Del mismo modo, los profesionales del fotoperiodismo tienen a su alcance soluciones para asegurar el origen y verosimilitud de su material a partir, por ejemplo, de los almacenes cifrados en blockchain. 
Así pues, el diálogo entre la profesión y la Academia debe ser constante para buscar soluciones comunes junto con las empresas tecnológicas. Las redacciones, de cualquier tamaño, deben implementar herramientas para comprobar la calidad de sus contenidos audiovisuales y los profesionales deben ser transparentes y dinámicos en sus rutinas de verificación. $\mathrm{O}$, al menos, deberán serlo quienes quieran seguir siendo considerados medios de calidad en el sistema de voces múltiples.

\section{Referencias}

Alper, Meryl (2014). War on Instagram: Framing conflict photojournalism with mobile photography apps. En: New Media \& Society, vol.16, nº8. Londres: Sage, 1233-1248.

Aparici, Roberto; García-Marín, David y Rincón-Manzano, Laura (2019). Noticias falsas, bulos y trending to-pics. Anatomía y estrategias de la desinformación en el conflicto catalán. En: El profesional de la información, vol.28, nº3. Barcelona: EPI, e280313

Canavilhas, João; Colussi, Juliana and Zita-Bacelar, Moura. (2019). Desinformación en las elecciones presidenciales 2018 en Brasil: un análisis de los grupos familiares en WhatsApp. En: El profesional de la información, vol.28, n ${ }^{\circ} 5$. Barcelona: EPI. Lavín de las Heras, Eva and Chivite Fernández, Javier (2015). Consecuencias de la manipulación fotográfica en las agencias de noticias: Associated Press, Reuters, France Press, European Pressphoto Agency y EFE. El caso del fotoperiodismo de guerra. En: Estudios sobre el Mensaje Periodístico, vol.21, nº1. Madrid: Universidad Complutense de Madrid: 333-351.

Lemos, André Luiz Martins; Cunha Bitencourt, Elias and Bastos dos Santos, João Guilherme (2020). Fake news as fake politics: the digital materialities of YouTube misinformation videos about Brazilian oil spill catastrophe. En: Media, Culture \& Society, vol.43, $\mathrm{n}^{0} 5$. Londres: Sage, 886-905.

Palomo, María Bella and Guerrero-García, Virginia (2015). The crisis of photojournalism: rethinking the profession in a participatory media ecosystem. En: Communication \& Society, vol.28, $\mathrm{n}^{\circ} 4$. Pamplona: Universidad de Navarra, 33-46.

Wardle, Claire y Derakhshan, Hossein (2017). Information disorder: Toward an interdisciplinary framework for research and policy making. Council of Europe report DGI(2017)09. Estrasburgo: Council of Europe. 